\title{
Phase-Transition-Enhanced Thermoelectric Transport in Rickardite Mineral $\mathrm{Cu}_{3-x} \mathrm{Te}_{2}$
}

Mujde Yahyaoglu, ${ }^{+, \neq}$Melis Ozen, ${ }^{+, \uparrow}$ Yurii Prots,,${ }^{\S}$ Oussama El Hamouli, ${ }^{\perp}$ Vahe Tshitoyan, ${ }^{\infty}$ Huiwen Ji, ${ }^{\infty}$ Ulrich Burkhardt, ${ }^{\S}$ Bertrand Lenoir, ${ }^{\perp}$ G. Jeffrey Snyder, ${ }^{\delta}$ Anubhav Jain, ${ }^{\xi}$ Christophe Candolfi, ${ }^{\perp}$ and Umut Aydemir ${ }^{*}, \phi$

${ }^{+}$Graduate School of Sciences and Engineering, Koç University, Istanbul 34450, Turkey

${ }^{\ddagger}$ Koç University Boron and Advanced Materials Application and Research Center (KUBAM), Istanbul 34450, Turkey

${ }^{\S}$ Max-Planck-Institut für Chemische Physik fester Stoffe, Dresden 01187, Germany

${ }^{\perp}$ Institut Jean Lamour, Université de Lorraine, Nancy Cedex 54011, France

${ }^{\infty}$ Materials Sciences Division, Lawrence Berkeley National Lab, Berkeley, California 94720, United States

${ }^{\xi}$ Energy Technologies Area, Lawrence Berkeley National Lab, Berkeley, California 94720, United States

${ }^{\delta}$ Department of Materials Science and Engineering, Northwestern University, Evanston, IL 60208, USA

${ }^{\phi}$ Department of Chemistry, Koç University, Istanbul 34450, Turkey

*Email: uaydemir@ku.edu.tr 


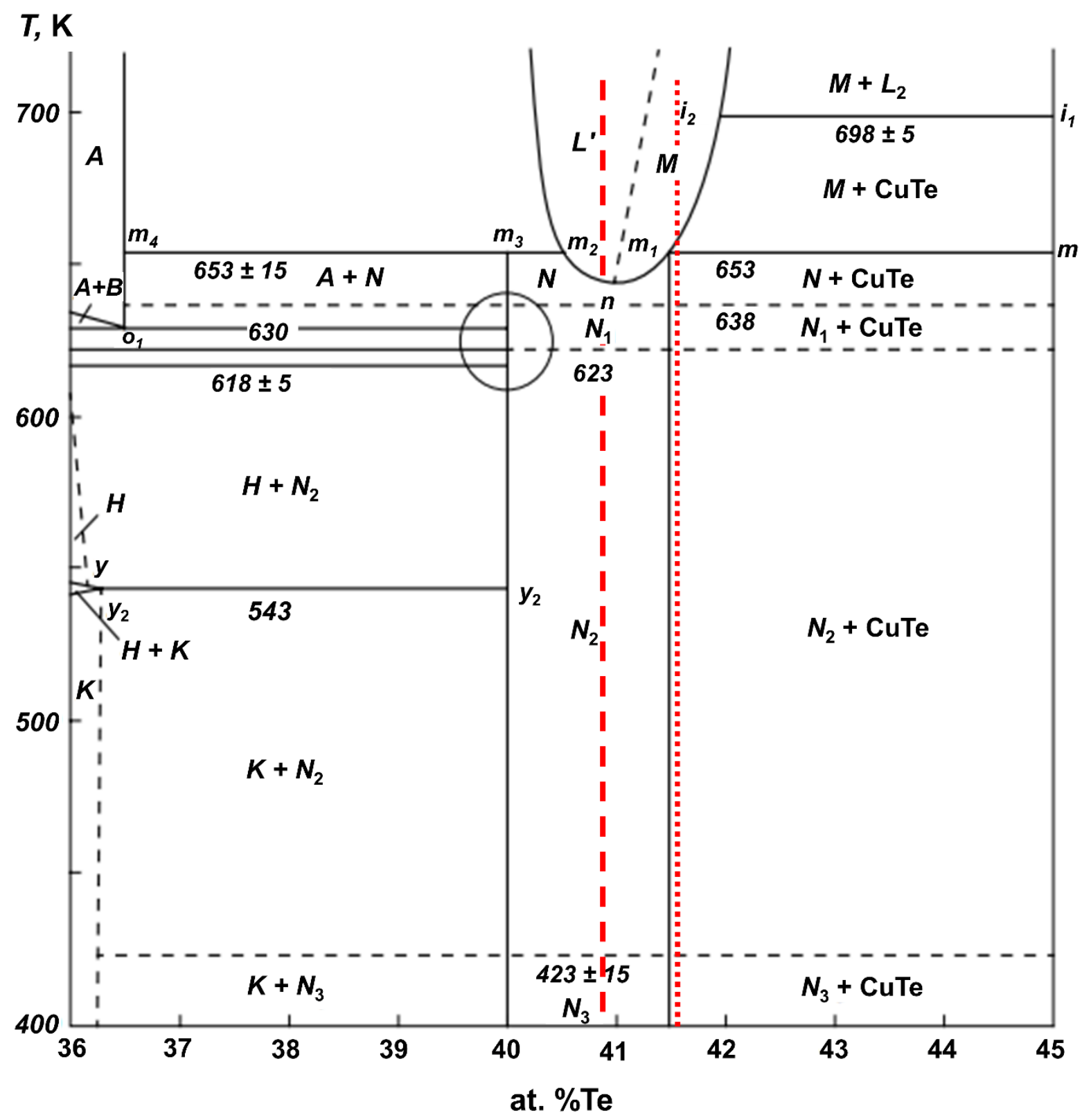

Figure S1. A section of binary phase diagram of the $\mathrm{Cu}$-Te system at around $\mathrm{Cu}_{3-x} \mathrm{Te}_{2}$ composition region ( $\sim 41$ at. $\% \mathrm{Te})$ and in the temperature range of $400-720 \mathrm{~K}^{1}\left(--: \mathrm{Cu}_{2.9} \mathrm{Te}_{2}, \cdots \cdot \mathrm{Cu}_{2.8} \mathrm{Te}_{2}\right)$.

${ }^{1}$ Pashinkin, A.; Fedorov, V., Phase equilibria in the Cu-Te system. Inorg. Mater. 2003, 39 (6), 539-554.

Table S1. Crystallographic data of $\mathrm{Cu}_{2.9} \mathrm{Te}_{2}$ 


\begin{tabular}{|c|c|}
\hline Composition & $\mathrm{Cu}_{2.89(1)} \mathrm{Te}_{2}$ \\
\hline Space group & $P m m n$ \\
\hline Formula units per unit cell, $Z$ & 2 \\
\hline \multicolumn{2}{|l|}{ Lattice parameters ${ }^{*}$} \\
\hline$a / \AA$ & $4.0067(2)$ \\
\hline$a / \AA$ & $3.9793(2)$ \\
\hline$c / \AA$ & $6.1120(3)$ \\
\hline$V / \AA^{3}$ & $97.449(8)$ \\
\hline Crystal form & irregular block \\
\hline Crystal size / $\mu \mathrm{m}$ & $25 \times 40 \times 60$ \\
\hline Diffraction system & RIGAKU AFC7 \\
\hline Detector & Saturn $724+$ CCD \\
\hline Radiation, $\lambda / \AA$ & $\operatorname{MoK} \alpha, 0.71073$ \\
\hline Scan; step / degree; $N$ (images) & $\varphi, 0.6,600$ \\
\hline Maximal $2 \theta /$ degree & 64.05 \\
\hline Absorption correction & Multiscan \\
\hline$T(\max ) / T(\min )$ & 2.36 \\
\hline Absorption coeff. $/ \mathrm{mm}^{-1}$ & 30.1 \\
\hline \multirow[t]{3}{*}{ Range in $h, k, l$} & $-5 \leq h \leq 3$ \\
\hline & $-5 \leq k \leq 4$ \\
\hline & $-8 \leq l \leq 8$ \\
\hline$N(h k l)$ measured & 729 \\
\hline$N(h k l)$ unique & 204 \\
\hline$R_{\text {int }}$ & 0.029 \\
\hline$N(h k l)$ observed & 203 \\
\hline Observation criteria & $F(h k l) \geq 4 \sigma(F)$ \\
\hline Refined parameters & 14 \\
\hline$R 1$ & 0.024 \\
\hline$w R 2$ & 0.060 \\
\hline Residual peaks / e $\AA^{-3}$ & $-1.44 / 1.53$ \\
\hline
\end{tabular}

'X-ray powder diffraction data (Huber Guinier G670 Camera, $\mathrm{CuK} \alpha_{1}$ radiation)

Table S2: Atomic coordinates, displacement parameters (in $\AA^{2}$ ) and site occupancy factor (SOF) of $\mathrm{Cu}_{2.9} \mathrm{Te}_{2}$ in $P m m n(R 1=0.024 ; w R 2=0.060)$. Standard deviations are provided in parentheses.

\begin{tabular}{|c|c|l|l|l|l|l|}
\hline Atom & Site & \multicolumn{1}{c|}{ SOF } & \multicolumn{1}{c|}{$\boldsymbol{x}$} & \multicolumn{1}{c|}{$\boldsymbol{y}$} & \multicolumn{1}{c|}{$\boldsymbol{z}$} & $\boldsymbol{U}_{\text {iso }}$ \\
\hline $\mathrm{Cu} 1$ & $2 a$ & 1 & $1 / 4$ & $3 / 4$ & $0.0000(1)$ & $0.0233(3)$ \\
\hline $\mathrm{Cu} 2$ & $2 b$ & $0.446(7)$ & $1 / 4$ & $1 / 4$ & $0.7048(4)$ & $0.0256(9)$ \\
\hline $\mathrm{Te} 1$ & $2 b$ & 1 & $1 / 4$ & $1 / 4$ & $0.28462(7)$ & $0.0197(2)$ \\
\hline
\end{tabular}




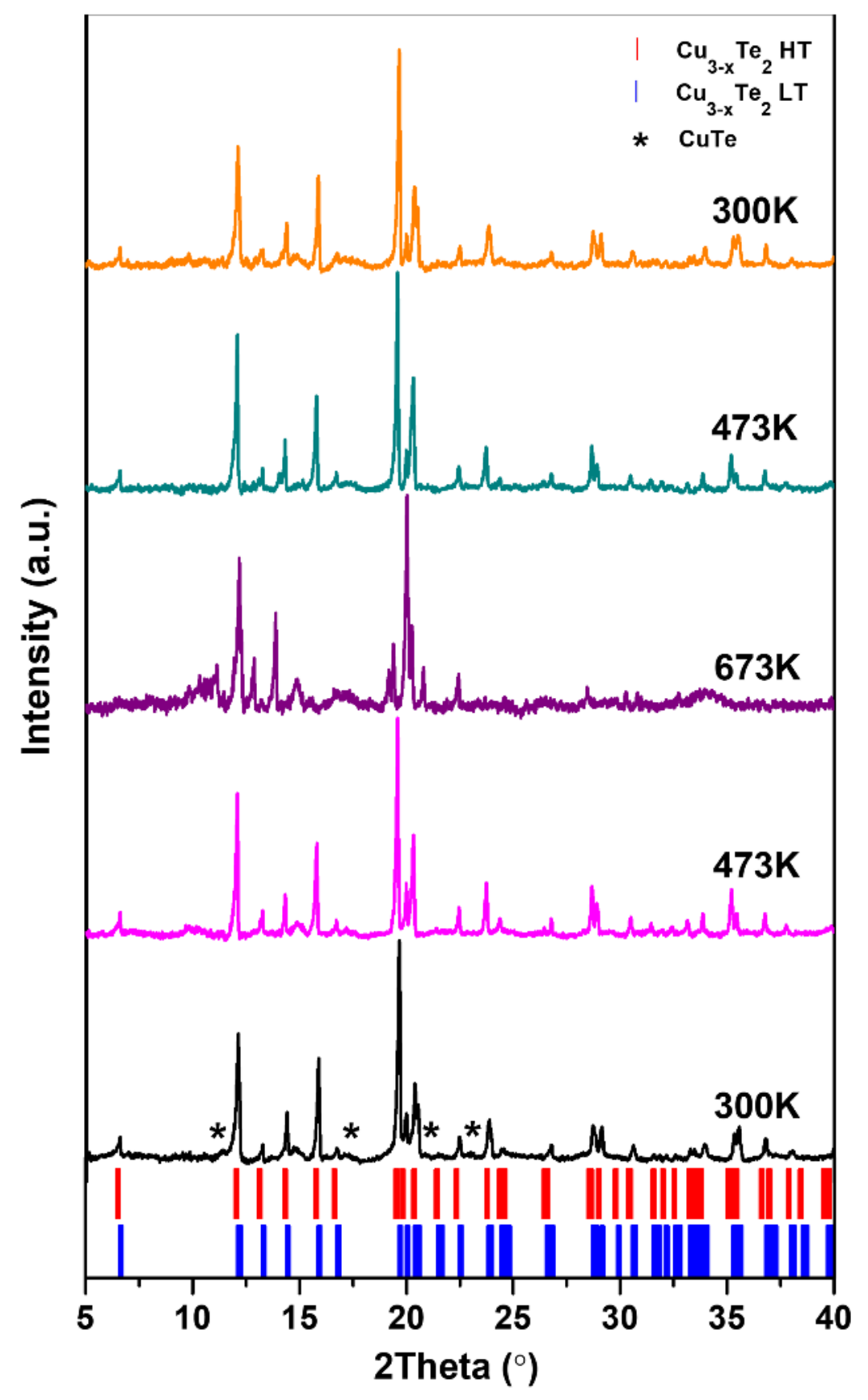

Figure S2. HT-XRD patterns ( $\mathrm{Mo} \mathrm{Ka}$ ) of a $\mathrm{Cu}_{2.8} \mathrm{Te}_{2}$ sample at $300 \mathrm{~K}, 473 \mathrm{~K}$, and $673 \mathrm{~K}$ upon heating and cooling (red and blue tick marks represent the theoretical peak positions of the tetragonal and orthorhombic structures, respectively). 


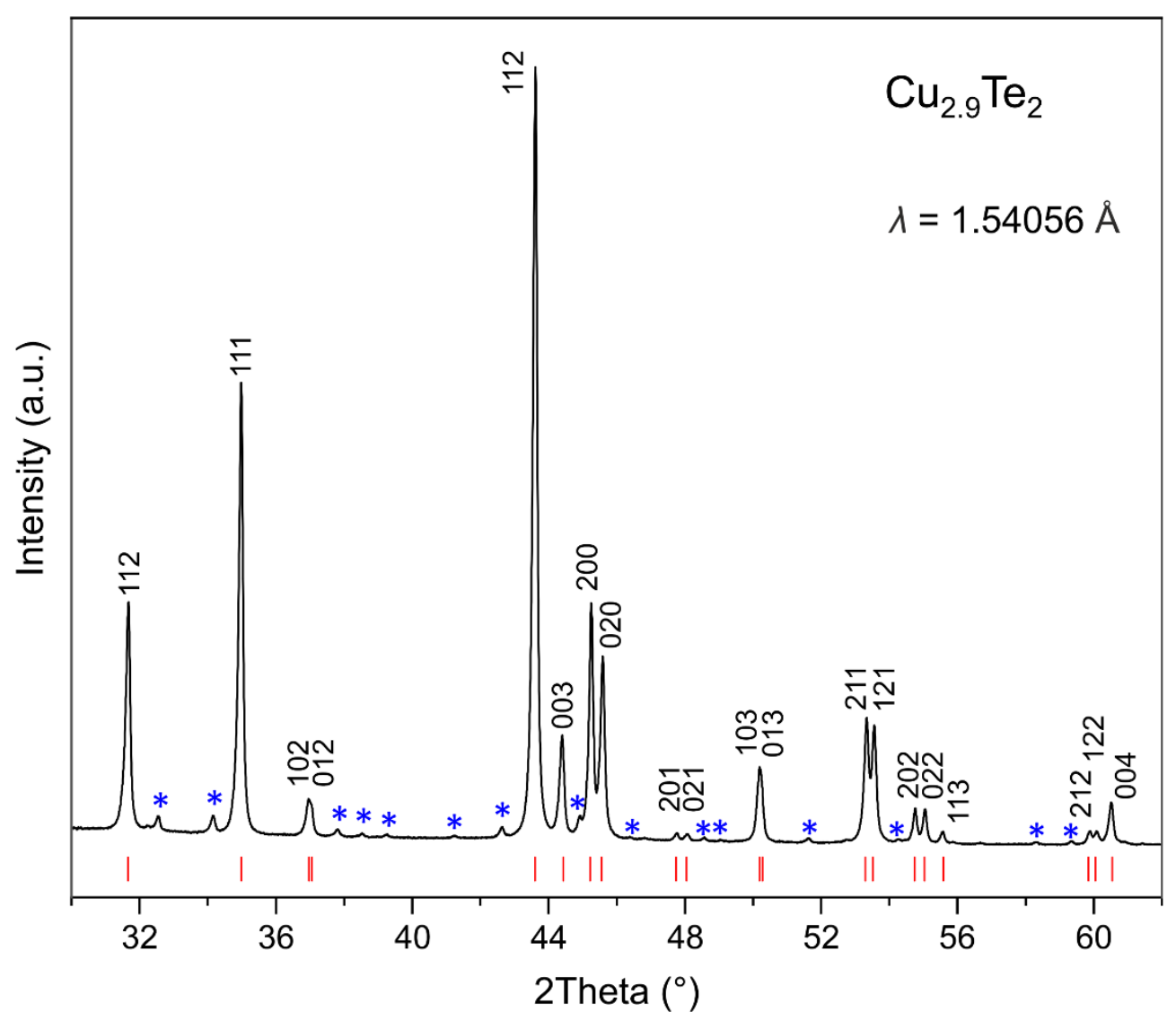

Figure S3. The selected region of the $\mathrm{X}$-ray powder pattern of $\mathrm{Cu}_{2.9} \mathrm{Te}_{2}$ recorded at ambient conditions (Huber Guinier G670 camera, $\mathrm{CuK} \alpha_{1}$ radiation). The ticks mark theoretical peak positions of calculated subcell (space group Pmmn, $a=4.0067 \AA, b=3.9793 \AA, c=6.1120 \AA$ ). The indices are displayed above the corresponding peaks. The observed splitting of the reflections is typical for the orthorhombic deformation of the tetragonal unit cell. The asterisks mark reflections that are compatible with the modulation vector $\mathrm{q}=[0$ $\sim 0.401 / 2]$. 


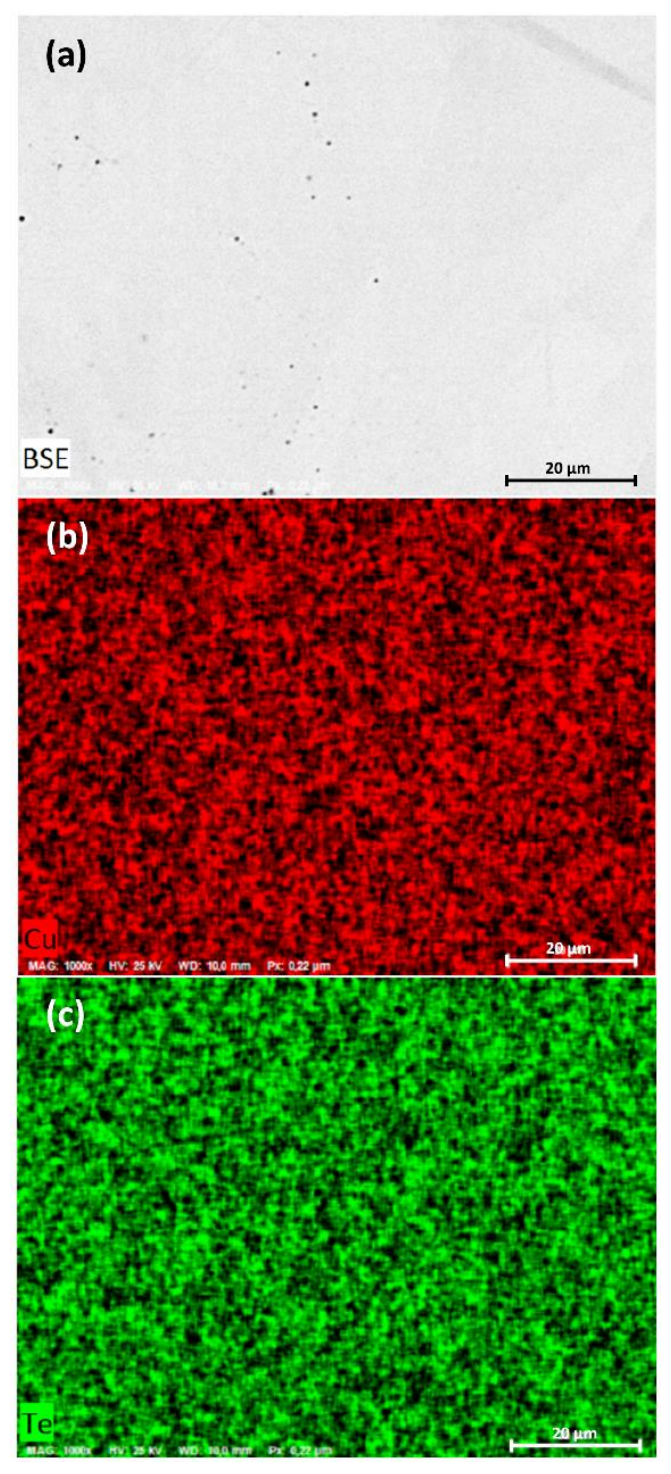

Figure S4. a) The back-scattered-electron image of $\mathrm{Cu}_{2.8} \mathrm{Te}_{2}$. Elemental mapping of the same sample showing the homogenous distribution of b) $\mathrm{Cu}$ and c) Te throughout the microstructure. Note that black spots on figure (a) belong to holes on the surface.

Table S3. The EDX analysis results of $\mathrm{Cu}_{2.8} \mathrm{Te}_{2}$ and $\mathrm{Cu}_{2.9} \mathrm{Te}_{2}$ (for the final composition, $\mathrm{Te}$ site is considered to be fully occupied).

\begin{tabular}{c|cccc|cccc}
\hline Spot \# & \multicolumn{4}{|c|}{$\mathrm{Cu}_{2.8} \mathrm{Te}_{2}($ nominal $)$} & \multicolumn{4}{c}{$\mathrm{Cu}_{2.9} \mathrm{Te}_{2}($ nominal) } \\
\hline $\mathbf{1}$ & $\mathbf{C u}$ & $\mathbf{T e}$ & Total & Composition & $\mathbf{C u}$ & $\mathbf{T e}$ & Total & Composition \\
\hline $\mathbf{2}$ & 58.4 & 41.6 & 100.0 & $\mathrm{Cu}_{2.80} \mathrm{Te}_{2}$ & 59.1 & 40.9 & 100.0 & $\mathrm{Cu}_{2.89} \mathrm{Te}_{2}$ \\
$\mathbf{3}$ & 58.5 & 41.5 & 100.0 & $\mathrm{Cu}_{2.82} \mathrm{Te}_{2}$ & 59.4 & 40.6 & 100.0 & $\mathrm{Cu}_{2.92} \mathrm{Te}_{2}$ \\
$\mathbf{4}$ & 58.2 & 41.8 & 100.0 & $\mathrm{Cu}_{2.78} \mathrm{Te}_{2}$ & 59.1 & 40.9 & 100.0 & $\mathrm{Cu}_{2.89} \mathrm{Te}_{2}$ \\
$\mathbf{5}$ & 58.4 & 41.6 & 100.0 & $\mathrm{Cu}_{2.80} \mathrm{Te}_{2}$ & 59.6 & 40.4 & 100.0 & $\mathrm{Cu}_{2.95} \mathrm{Te}_{2}$ \\
& & 41.6 & 100.0 & $\mathrm{Cu}_{2.80} \mathrm{Te}_{2}$ & 59.5 & 40.5 & 100.0 & $\mathrm{Cu}_{2.93} \mathrm{Te}_{2}$
\end{tabular}




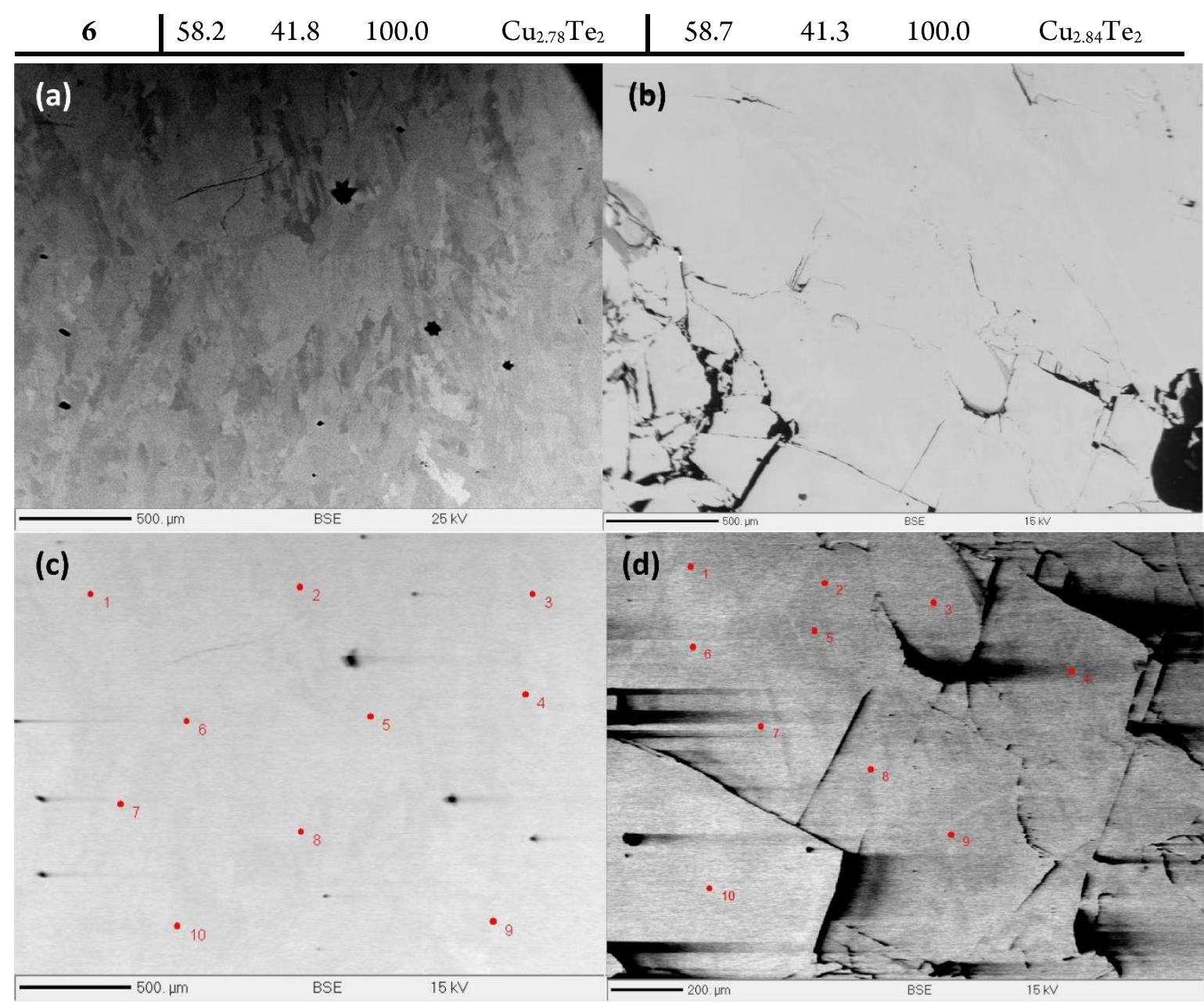

Figure S5. SEM images of a) $\mathrm{Cu}_{2.8} \mathrm{Te}_{2}$ and b) $\mathrm{Cu}_{2.9} \mathrm{Te}_{2}$ and with corresponding 10 different spots used for WDS analysis of c) $\mathrm{Cu}_{2.8} \mathrm{Te}_{2}$ and d) $\mathrm{Cu}_{2.9} \mathrm{Te}_{2}$.

Table S4. The WDS analysis results of $\mathrm{Cu}_{2.8} \mathrm{Te}_{2}$ and $\mathrm{Cu}_{2.9} \mathrm{Te}_{2}$.

\begin{tabular}{c|ccc|ccc}
\hline \multicolumn{3}{c|}{$\mathrm{Cu}_{2.8} \mathrm{Te}_{2}$ (nominal) } & \multicolumn{3}{c}{$\mathrm{Cu}_{2.9} \mathrm{Te}_{2}$ (nominal) } \\
& Atomic \% & Weight \% & StdDev wt\% & Atomic \% & Weight \% & StdDev wt\% \\
\hline $\mathbf{C u}$ & 58.6 & 41.4 & 0.2 & 58.7 & 41.5 & 0.2 \\
Te & 41.4 & 58.6 & 0.2 & 41.3 & 58.5 & 0.2 \\
Total & 100.0 & 100.0 & & 100.0 & 100.0 & \\
\hline & \multicolumn{3}{c|}{$\mathbf{C u}_{2.83(1)} \mathbf{T e}_{2}$} & \multicolumn{3}{c}{$\mathbf{C u}_{2.84(1)} \mathbf{T e}_{2}$} \\
\hline
\end{tabular}




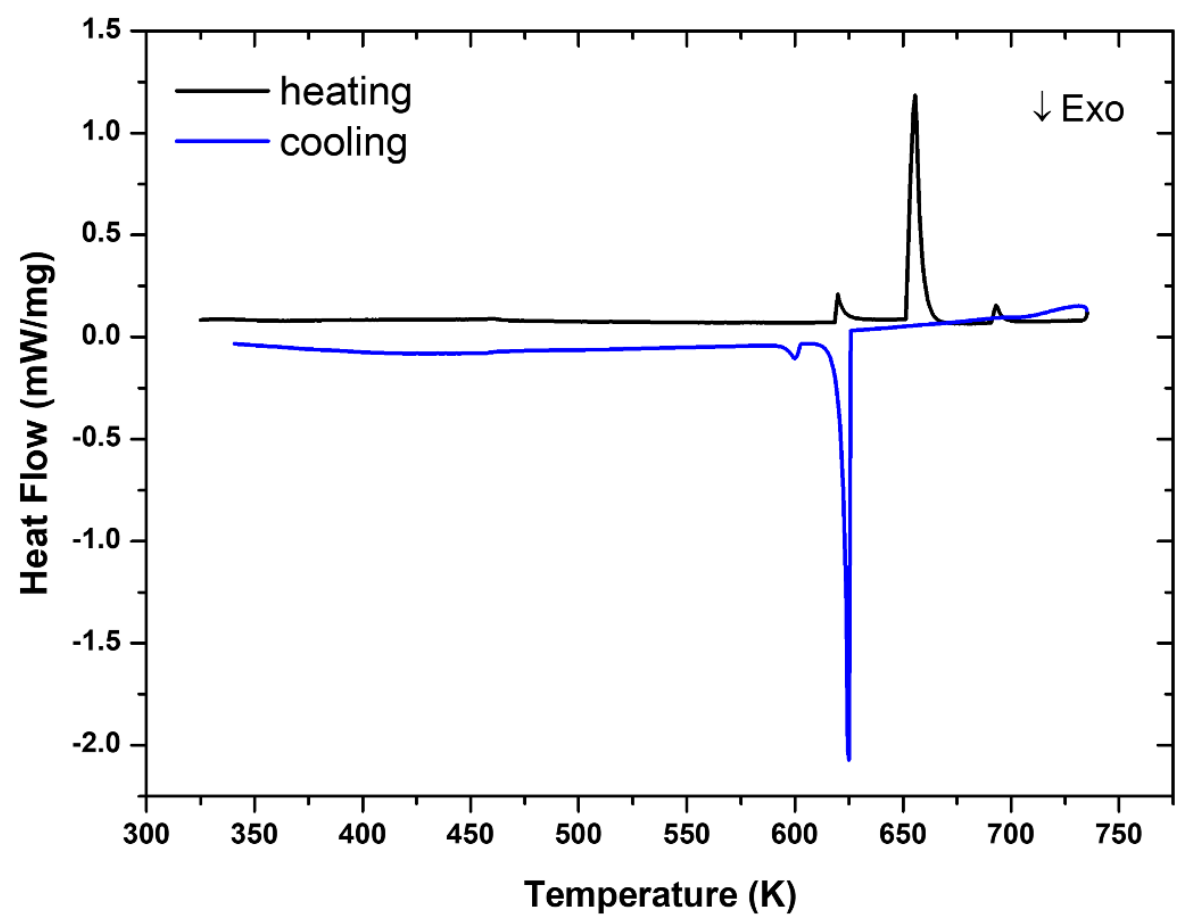

Figure S6. DSC thermogram of $\mathrm{Cu}_{2.8} \mathrm{Te}_{2}$ with heating and cooling rate of $10 \mathrm{~K} \mathrm{~min}^{-1}$.

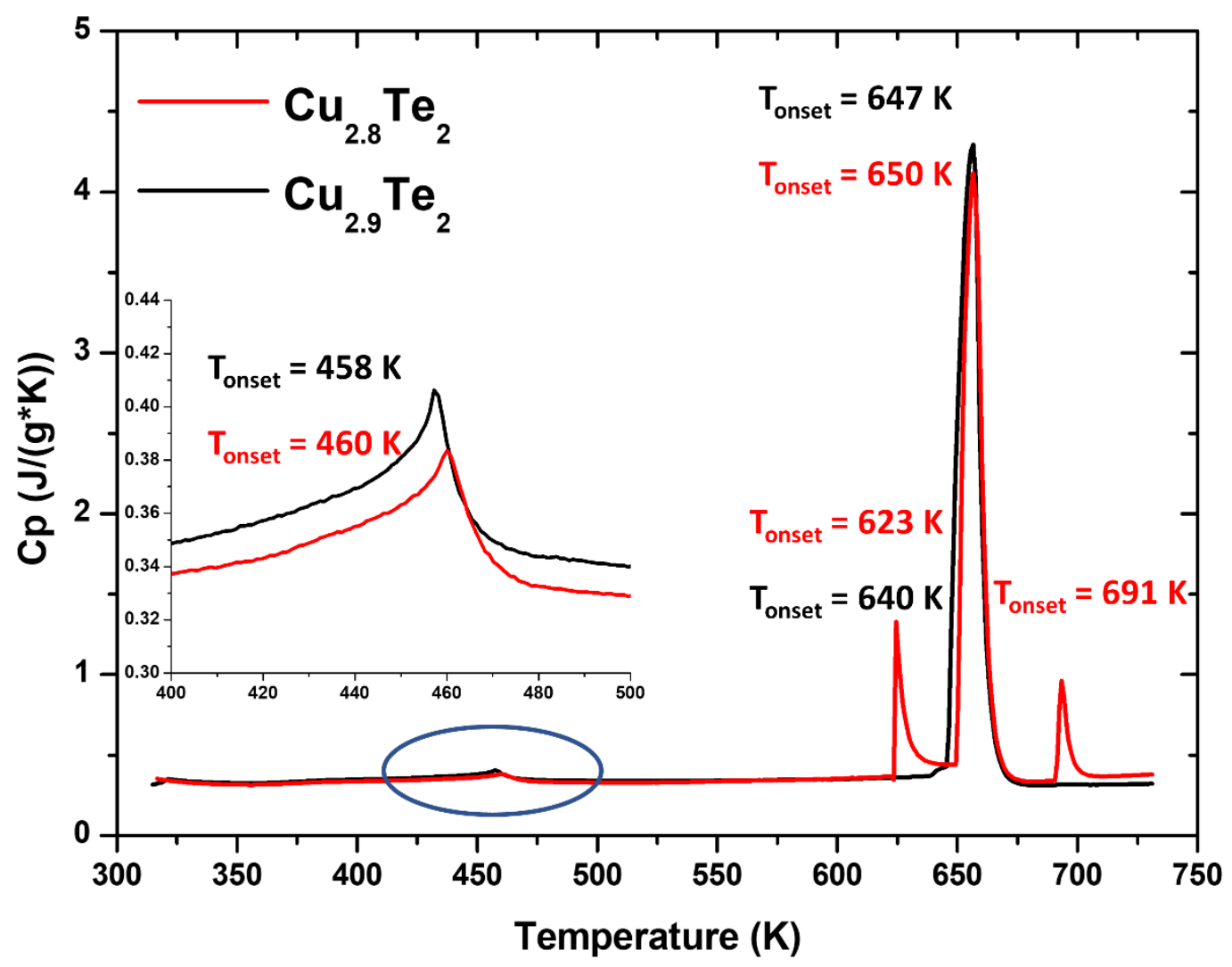

Figure S7. $\mathrm{Cp}$ of $\mathrm{Cu}_{2.8} \mathrm{Te}_{2}$ and $\mathrm{Cu}_{2.9} \mathrm{Te}_{2}$ (inset graph shows corresponding blue marked phase transition region). 

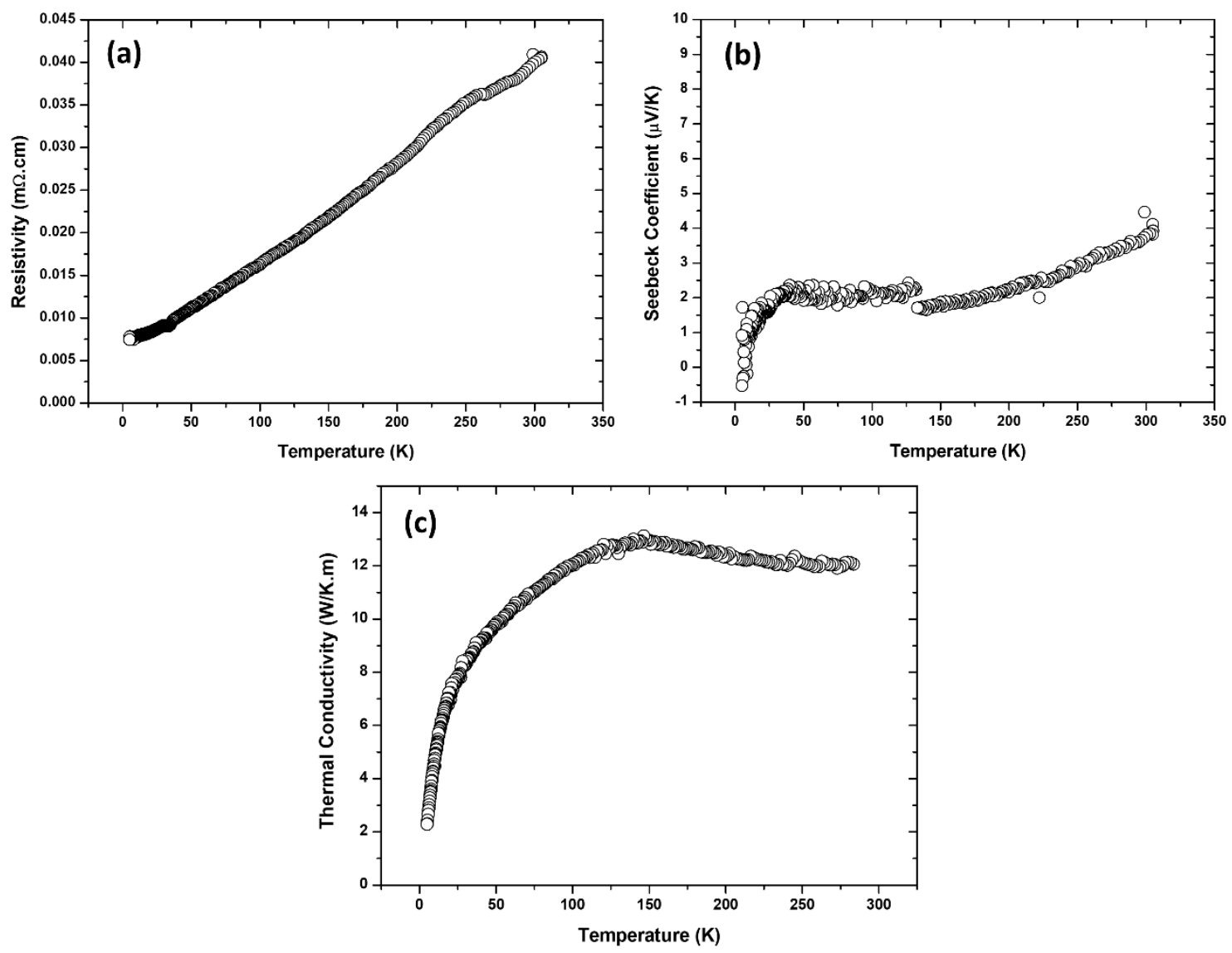

Figure S8. Low temperature electronic and thermal transport data of $\mathrm{Cu}_{2.8} \mathrm{Te}_{2}$. 

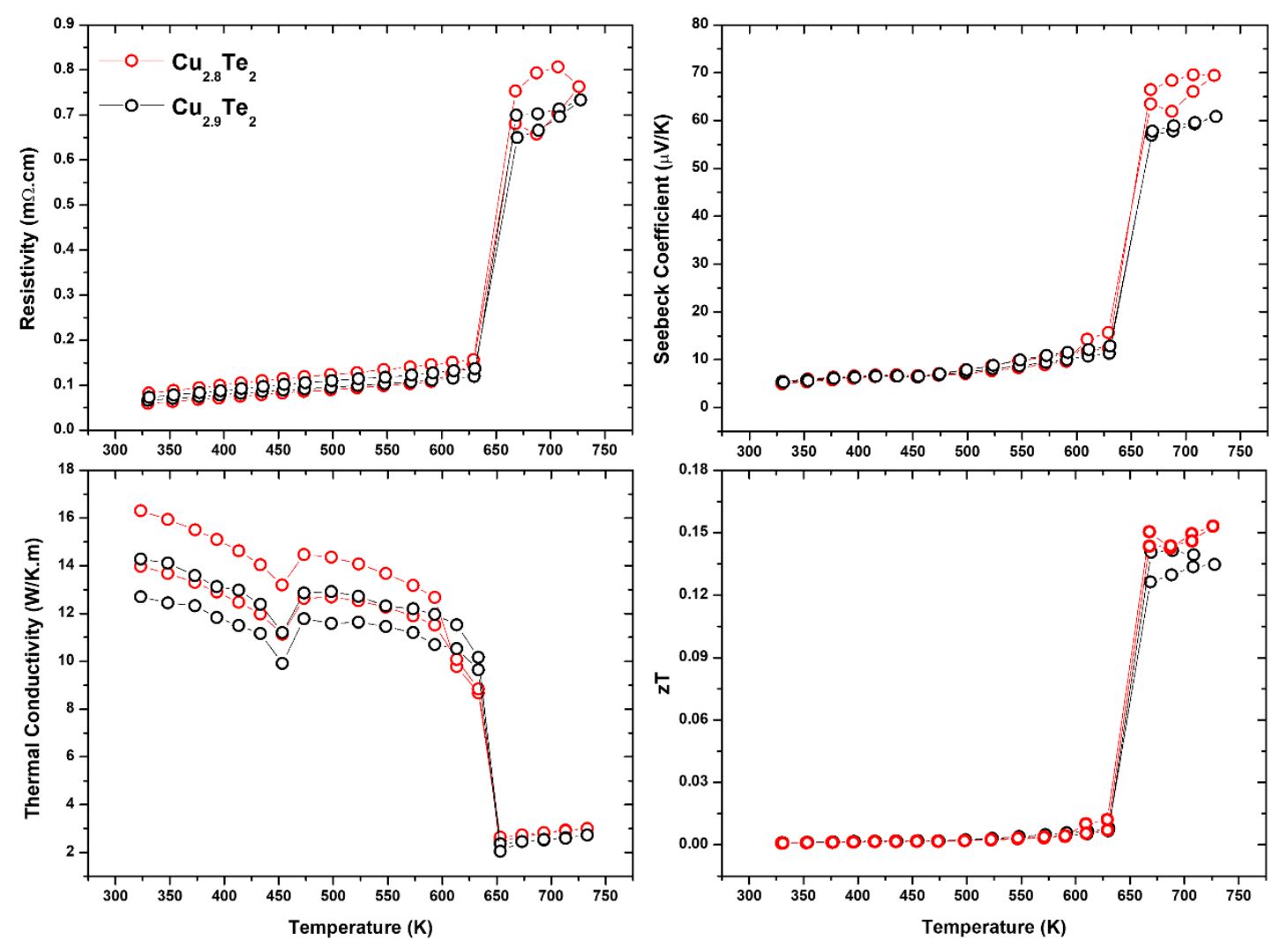

Figure S9. Comparison of the electronic and thermal transport data of $\mathrm{Cu}_{2.8} \mathrm{Te}_{2}$ and $\mathrm{Cu}_{2.9} \mathrm{Te}_{2}$.
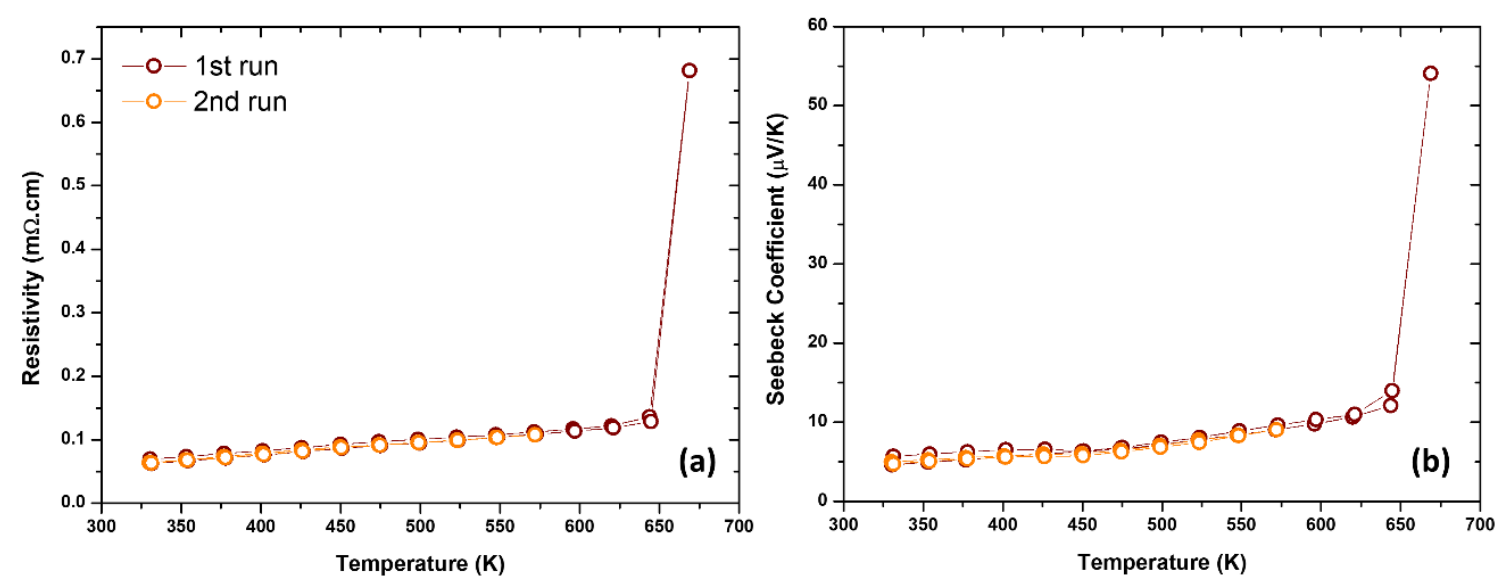

Figure S10. a) Resistivity and b) Seebeck coefficient of $\mathrm{Cu}_{2.9} \mathrm{Te}_{2}$ with the second cycle performed to the temperature of $573 \mathrm{~K}$. 

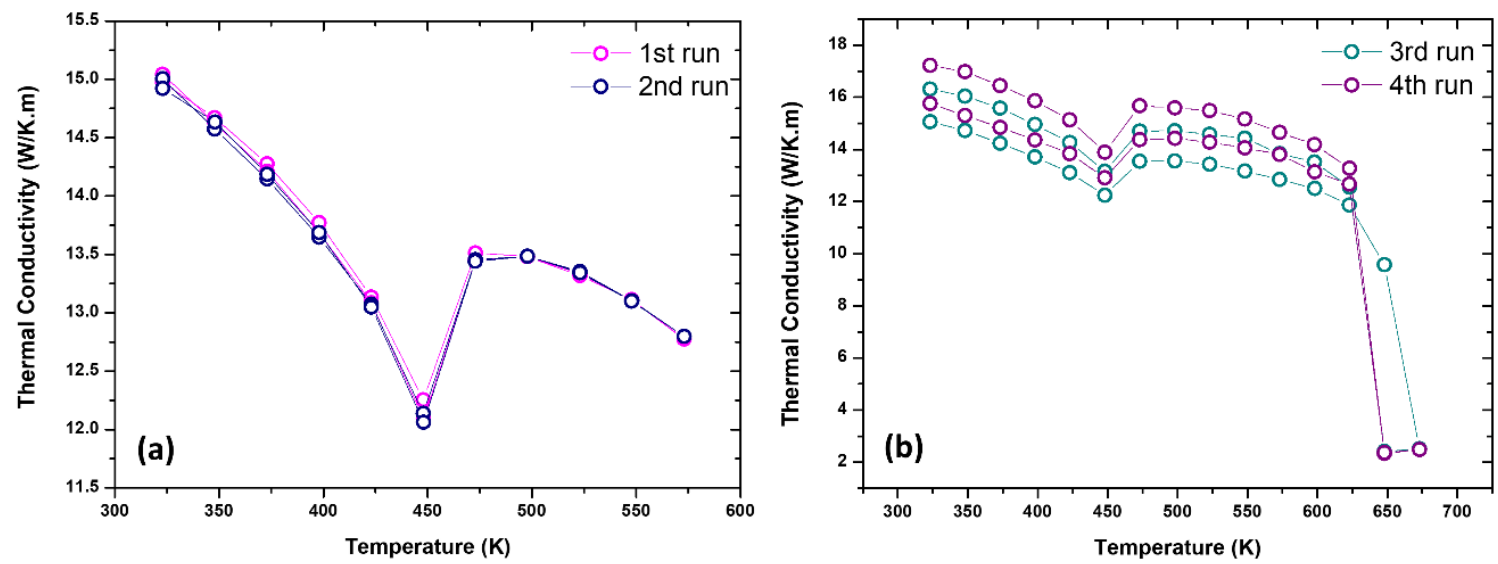

Figure S1 1. The repeated thermal conductivity measurements of $\mathrm{Cu}_{2.9} \mathrm{Te}_{2}$ to the temperature of a) $573 \mathrm{~K}$ and b) $673 \mathrm{~K}$.

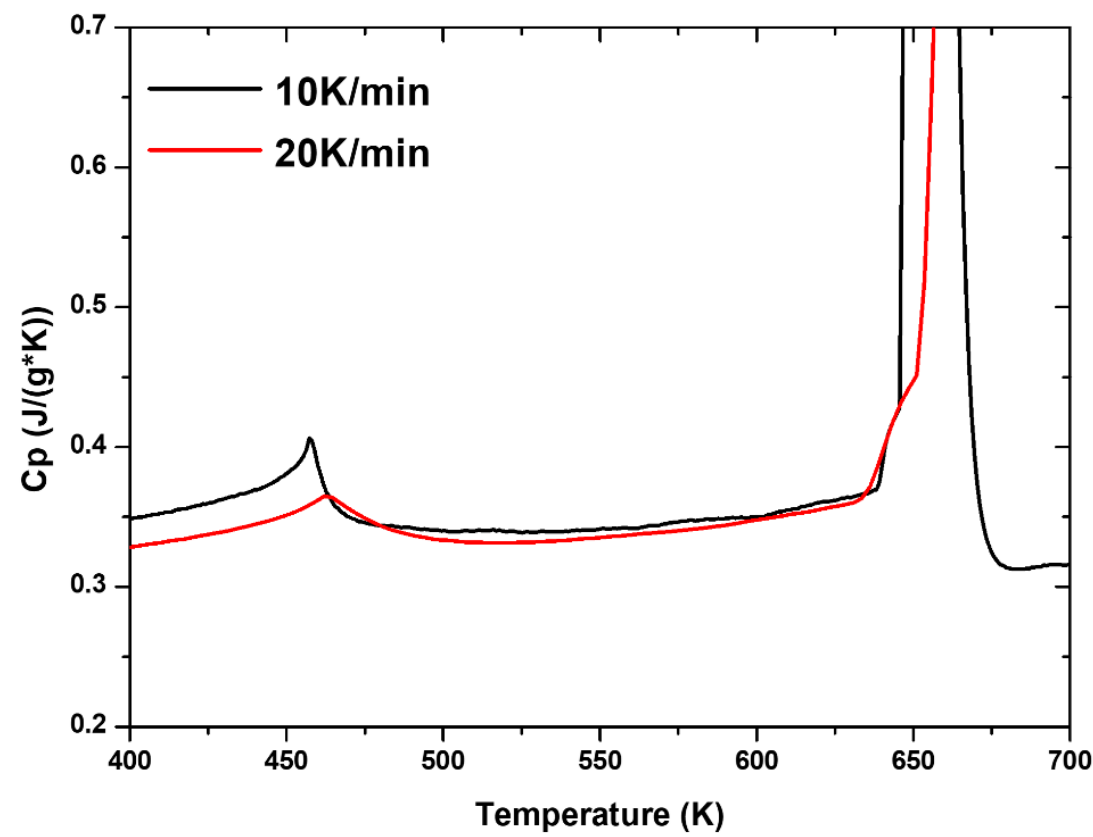

Figure S12. The $\mathrm{C}_{\mathrm{p}}$ of $\mathrm{Cu}_{2.9} \mathrm{Te}_{2}$ with heating rates of $10 \mathrm{~K} / \mathrm{min}$ and $20 \mathrm{~K} / \mathrm{min}$. 